\title{
Revisionary antireflux metal stent placement for stent occlusion after endoscopic ultrasound-guided hepaticojejunostomy
}

Endoscopic ultrasound-guided biliary drainage (EUS-BD) has been recently recognized as a new treatment option for obstructive jaundice with a surgically altered anatomy [1]. However, stent occlusion has been reported to occur in $10.7 \%-25 \%$ of cases following EUS-BD $[2,3]$. Reflux of food residue from the gastrointestinal tract into the stent is thought to be causing stent occlusion; therefore, a stent that can prevent food reflux needs to be developed to ensure longer-lasting stent patency. We report the first case in which revisionary placement of an antireflux metal stent was useful for stent occlusion following EUS-BD ( video 1).

An 85-year-old man who had undergone distal gastrectomy with Billroth II reconstruction for gastric cancer presented with biliary obstruction due to lymph node metastasis. For biliary drainage, EUS-guided hepaticojejunostomy (HJS) was performed via the afferent limb. A dedicated 7-Fr $\times 14-\mathrm{cm}$ plastic stent (TYPE-IT stent; Gadelius Medical, Tokyo, Japan) was placed without complications ( $\triangleright$ Fig. 1). However, 2 months later, the patient presented with recurrence of jaundice and cholangitis. Endoscopic reintervention for stent occlusion was attempted using a forward-viewing gastroscope. A 0.025-inch guidewire was inserted into the biliary tree along the HJS stent ( $\triangleright$ Fig. 2); the stent was removed with grasping forceps. After cholangiography, a $10 \times 80-\mathrm{mm}$ antireflux covered metal stent (Niti-S Biliary Long-Covered ComVi Stent; Taewoong Medical, Gimpo, Korea) was placed through the HJS fistula ( Fig.3). This stent has a 7-mm-long funnel-shaped antireflux valve designed to prevent food reflux [4]. The patient completely recovered within a few days; currently, at over 6 months after the procedure, he is continuing chemotherapy without stent dysfunction ( $>$ Fig.4).

Antireflux biliary stents have been reported to be useful in transpapillary

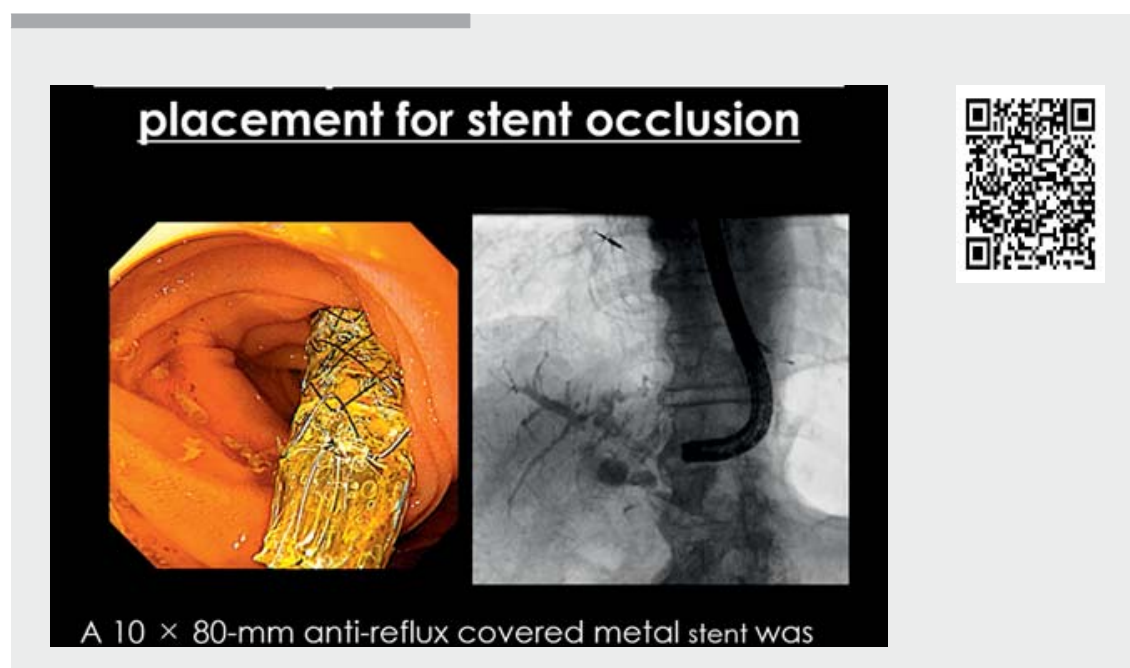

Video 1 Revisionary antireflux covered metal stent placement for stent occlusion after endoscopic ultrasound-guided hepaticojejunostomy.
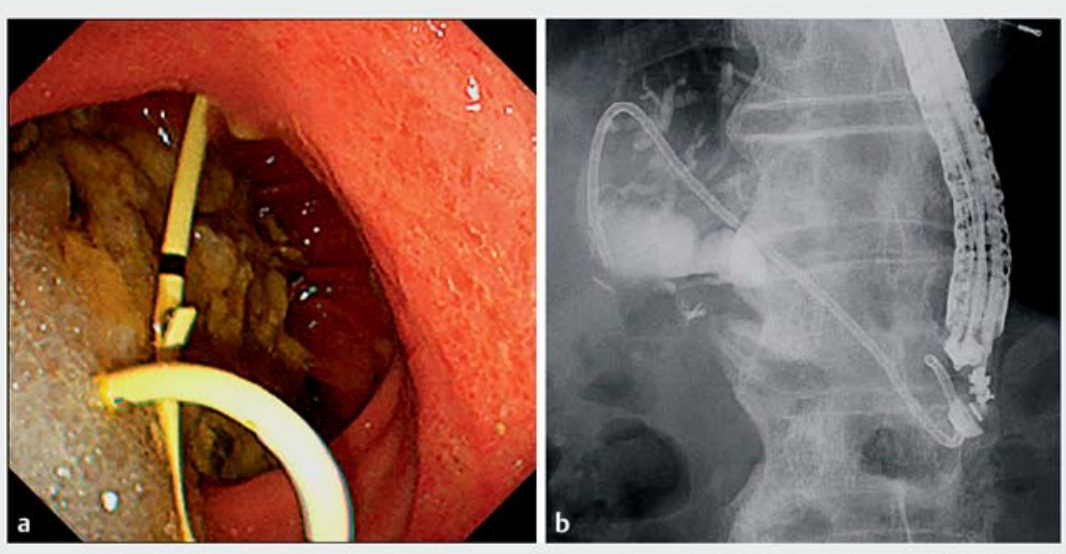

Fig. 1 Endoscopic ultrasound-guided hepaticojejunostomy (HJS) performed using a dedicated 7-Fr $\times 14-\mathrm{cm}$ plastic stent. a Endoscopic view, b fluoroscopic view.

drainage under ERCP $[4,5]$, but their usefulness in transmural drainage under EUS is unknown. The case reported here indicates that placement of an antireflux metal stent could be useful to manage stent dysfunction following EUS-BD and achieve long-term stent patency.

Endoscopy_UCTN_Code_TTT_1AS_2AG
Competing interests

None 


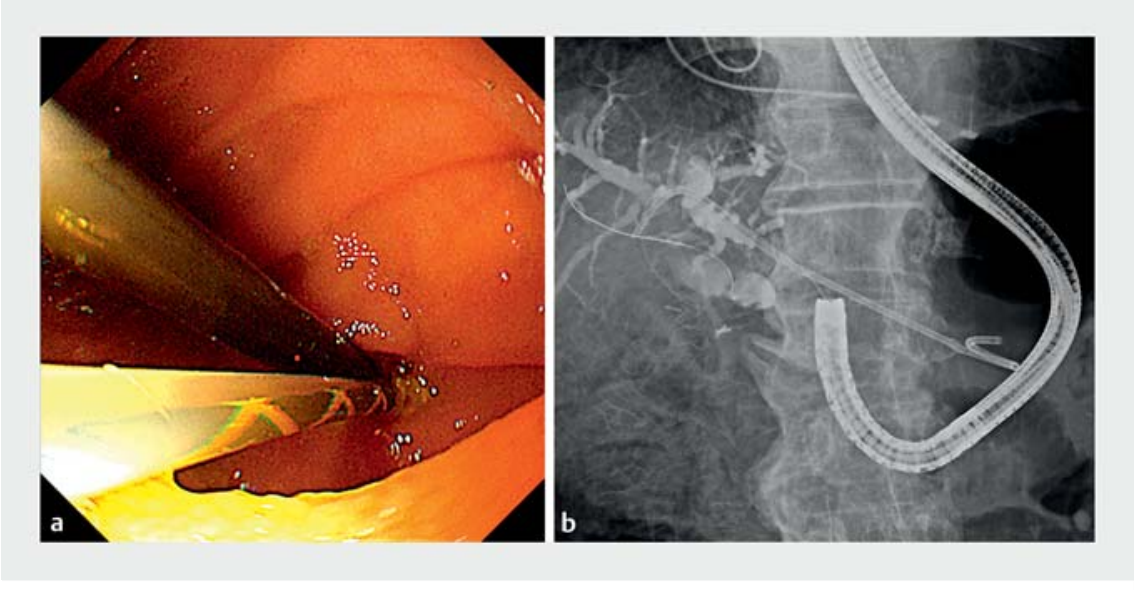

- Fig. 2 Endoscopic reintervention for the treatment of stent occlusion after endoscopic ultrasound-guided HJS. A 0.025 -inch guidewire was advanced along the HJS stent into the biliary tree. a Endoscopic view, b fluoroscopic view.
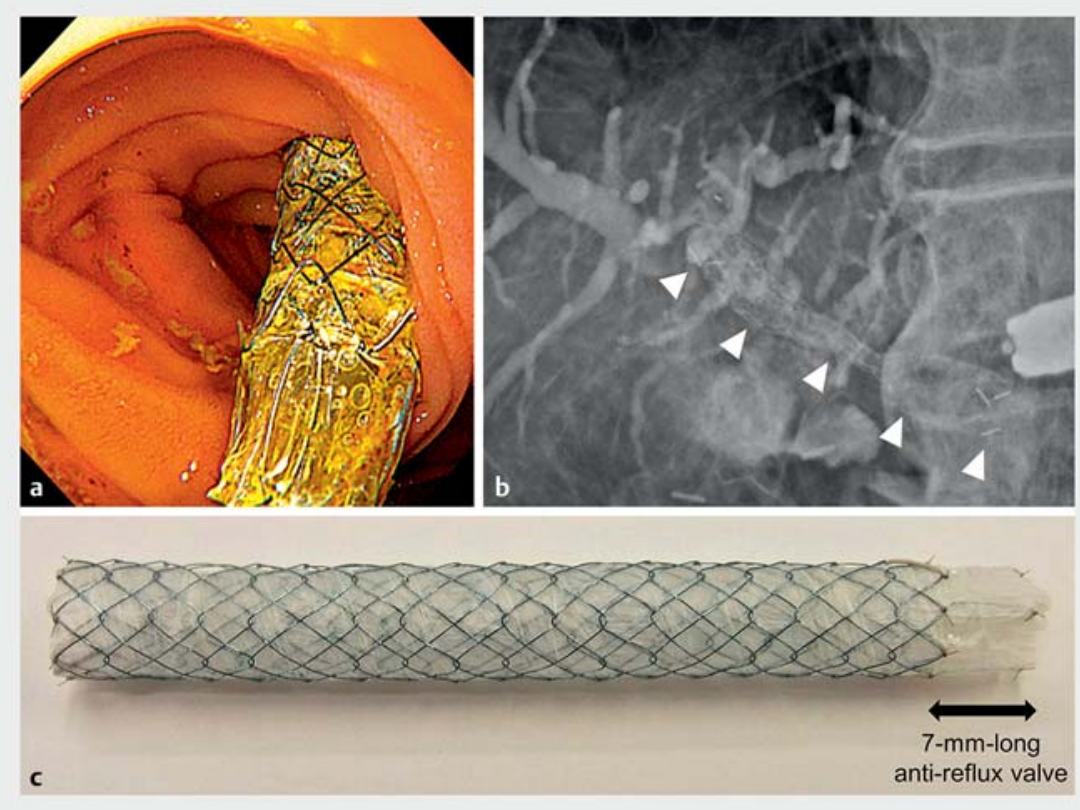

- Fig. 3 Revisionary placement of a $10 \times 80-\mathrm{mm}$ antireflux covered metal stent equipped with a 7-mm-long funnel-shaped antireflux valve (Niti-S Biliary Long-Covered ComVi Stent; Taewoong Medical, Gimpo, Korea) through a fistula. a Endoscopic view, b fluoroscopic view, c photograph of the stent.

The authors

Kosuke Minaga, Mamoru Takenaka, Ayana Okamoto, Shunsuke Omoto, Ken Kamata, Kentaro Yamao, Masatoshi Kudo

Department of Gastroenterology and Hepatology, Kindai University Faculty of Medicine, Osaka-Sayama, Japan

\section{Corresponding author}

\author{
Kosuke Minaga, MD, PhD \\ Department of Gastroenterology and \\ Hepatology, Kindai University Faculty of \\ Medicine, 377-2 Ohno-Higashi, Osaka- \\ Sayama, 589-8511, Japan \\ Fax: +81-72-367-2880 \\ kousukeminaga@med.kindai.ac.jp
}

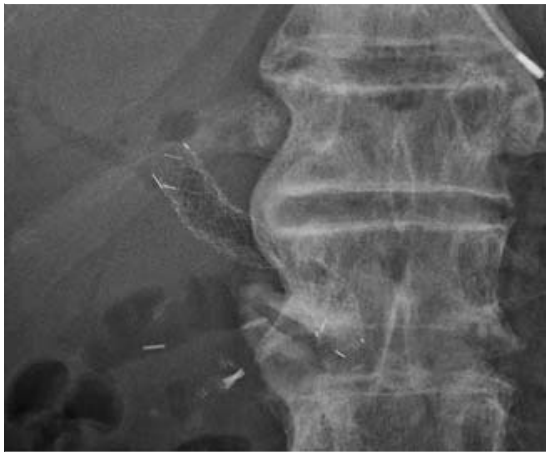

- Fig. 4 Fluoroscopic image obtained 6 months after antireflux metal stent placement shows pneumobilia (white arrowheads). No stent migration or dislocation is seen.

\section{References}

[1] Minaga K, Kitano M. Recent advances in endoscopic ultrasound-guided biliary drainage. Dig Endosc 2018; 30: 38-47

[2] Kawakubo K, Isayama H, Kato H et al. Multicenter retrospective study of endoscopic ultrasound-guided biliary drainage for malignant biliary obstruction in Japan. J Hepatobiliary Pancreat Sci 2014; 21: 328-334

[3] Hedjoudje A, Sportes A, Grabar S et al. Outcomes of endoscopic ultrasound-guided biliary drainage: a systematic review and meta-analysis. United European Gastroenterol J 2019; 7: 60-68

[4] Hamada T, Isayama H, Nakai Y et al. Antireflux metal stent as a first-line metal stent for distal malignant biliary obstruction: a pilot study. Gut Liver 2017; 11: 142-148

[5] Lee YN, Moon JH, Choi H] et al. Effectiveness of a newly designed antireflux valve metal stent to reduce duodenobiliary reflux in patients with unresectable distal malignant biliary obstruction: a randomized, controlled pilot study (with videos). Gastrointest Endosc 2016; 83: 404-412

\section{Bibliography}

DOI https://doi.org/10.1055/a-1032-8272

Published online: 15.11.2019

Endoscopy 2020; 52: E152-E153

(c) Georg Thieme Verlag KG

Stuttgart - New York

ISSN 0013-726X 